\title{
Active Disturbance Rejection Control for Double Pump Direct Driven Hydraulics
}

\author{
Shuzhong Zhang ${ }^{1}{ }^{*}$, Angen $\mathrm{Wu}^{1}$ and Fuquan Dai ${ }^{2}$ \\ 1 School of Mechanical and Automotive Engineering, Fujian University of Technology, Fuzhou, China; \\ shuzhong_zhang@outlook.com; angen_wu@outlook.com \\ 2 Fujian Haiyuan Composite Materials Technology Co., Ltd. \\ * Correspondence: shuzhong_zhang@outlook.com; Tel.: +86-591-228-63232
}

\begin{abstract}
As the energy crisis and further development of the electro-hydraulicactuator driven by servo motor, double-pump direct driven hydraulics (DDH) was brought forward, which mainly comprises of a servo motor, double fixed displacement pumps, a differential cylinder, a lowpressurized tank and auxiliary valves. To address the problems caused by uncertain parameters and unknown external disturbances of DDH, this paper proposed a control method adopting active disturbance rejection control (ADRC). Firstly, a mathematical model, including a DDH unit and a micro-crane, w as created and modelled in MATLAB/Simulink. Further, the model w as verified by measurement. After that, the state-space equation model of the system was derived based on its mathematical model and a third-order ADRC was designed using the constructed system statespace equation. Additionally, tracking-differentiator (TD) w as employed to process the input signal transiently to avoid unnecessary oscillations, and the extended state observer (ESO) was used to accurately estimate the influence of the uncertainty and compensateby nonlinear feedback control law (NFCL). Moreover, the proposed ADRC or Proportional-Integral-Differential(PID) control was combined with the mathematical model of a micro-crane. Finally, the simulations were performed under varying loads, and the system position tracking performance were analyzed and compared. The results show that the ADRC can sufficiently suppress the unknown external disturbance, has the advantages of robustness and improves the position tracking precision.
\end{abstract}

Keywords: Direct driven hydruics (DDH); Differential cylinder; Tracking-differentiator (TD); Extended stateobserver (ESO); Active disturbance rejection control (ADRC); Position control.

\section{Introduction}

The electro-hydraulic servo system can be roughly divided into tw o categories: valve-controlled system and pump-controlled system. The valve-controlled system has the characteristics of fast dynamic response and high control accuracy, but it has disadvantages such as significantly throttling loss, low system efficiency, and severe heating. Compared with the valve-controlled system, the pump-controlled system basically eliminates the throttling loss. Hence, it significantly improves system efficiency and has the characteristics of compactness and high system integration [1,2]. In recent years, machines have to be energy efficient due to limited and high-priced energy resources together with the increasing sensitivity of environmental issues [3, 4]. Hence, pump-controlled system techniques have become the centre of the focus $[5,6]$.

How ever, in the pump-controlled differential cylinder system, unbalanced flow caused by the unequal effective cross-section area of the two chambers. Many researches were carried out on it, 
such as using pilot-operated check valve or solenoid-operated reversing valve [7, 8], developing asymmetric flow distribution pump [9], proposing double-pump or multi-pump compensation circuit [10-12] to solve flow imbalanced problem. Among them, the double-pump direct driven hydraulic (DDH) system can better improve the dynamic performance and stability of the system. Then, when addressing the problem of flow imbalance, the time-varying and nonlinearity of the pump-controlled system also need to be solved. Hence, many control methods were proposed, such as adaptive fuzzy control [13], control based on disturbance observer [14,15], adaptivebackstepping control or iterative backstep control [16-18].

As discussed above, the DDH can effectively solve the problem of flow mismatch, but control performance of the system is affected by parameter uncertainty. Therefore, this paper proposed a control method adopting active disturbance rejection control (ADRC) for DDH. Firstly, Section 2 introduces the principle of the DDH and establishs the mathematical model of a micro-crane, and derives the system state-space equation. Then, Section 3 gives the design procedure of the proposed ADRC controller based on the system state-space. Section 4 performs simulation and compares the tracking performance of the ADRC controller with Proportional-Integral-Differential (PID) controller. Finally, Section 5 draws some conclusions.

\section{Modelling}

\subsection{Working principle of $D D H$}

The DDH is mainly composed of a permanent magnet synchronous motor, two bi-directional pumps, a hydraulic accumulator, two check valves, and two pressure relief valves, as shown in Figure 1 and Table 1 . The two pumps are driven by permanent magnet synchronous motor; the hydraulic accumulator is installed between the tw o pumps to make the system more compact; two check valves are used to prevent cavitation, and two pressure relief valves are used for safety purposes.

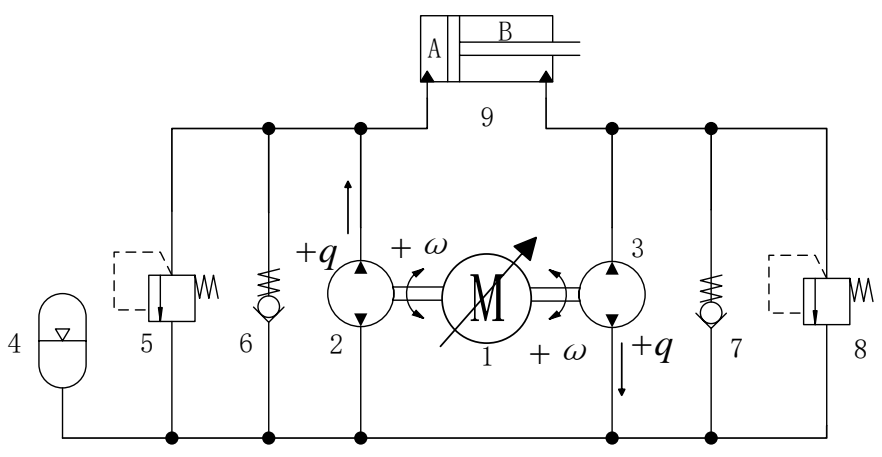

Figure 1. Schematic diagram of DDH $[10,19]$

Table 1. List of the components (see Figure 1)

\begin{tabular}{cccc}
\hline No. & Component & No. & Component \\
\hline 1 & $\begin{array}{c}\text { Permanent magnet } \\
\text { synchronous motor }\end{array}$ & 5,8 & Pressure relief valve \\
2 & A-side pump & 6,7 & Checkvalve \\
3 & B-side pump & 9 & Hydraulic cylinder \\
4 & Hydraulic accumulator & & \\
\hline
\end{tabular}




\subsection{DDH Model}

The DDH models mainly includes pump, cylinder. In the model, the following assumptions are given: the hydraulic cylinder leakage is zero; the hydraulic cylinder load is an inertial load, and there is no elastic load.

\subsubsection{Pump model}

The flow equation of the pump is given by:

$$
\begin{aligned}
& Q_{\mathrm{A}}=\eta \omega D_{\mathrm{pA}} \\
& Q_{\mathrm{B}}=-\eta \omega D_{\mathrm{pB}}
\end{aligned}
$$

where $\eta$ is the volumetric efficiency of the pump, and it is set to be $85 \%$; $\omega$ is the angular velocity, $D_{\mathrm{p}}$ is the volumetric displacement.

\subsubsection{Cylinder model}

The flow equation of the hydraulic cylinder can be expressed by:

$$
\begin{gathered}
q_{\mathrm{A}}=A_{\mathrm{A}} \dot{x}+\frac{V_{1}}{\beta_{\mathrm{e}}} \dot{p}_{\mathrm{A}} \\
-q_{\mathrm{B}}=A_{\mathrm{B}} \dot{x}+\frac{V_{2}}{\beta_{\mathrm{e}}} \dot{p}_{\mathrm{B}} \\
V_{1}=V_{10}+A_{\mathrm{A}} x \\
V_{2}=V_{20}+A_{\mathrm{B}} x
\end{gathered}
$$

whree $q_{A}$ and $q_{\mathrm{B}}$ are the flow of the chamber $A$ and chamber $B, A_{\mathrm{A}}$ is the piston area, $A_{\mathrm{B}}$ is the difference of piston and piston rod area, $x$ is the absolute position of the piston $p_{\mathrm{A}}$ and $p_{\mathrm{B}}$ are the pressure pressure of the chamber $A$ and chamber $B, \beta_{\mathrm{e}}$ is the effective bulk modulus, $V_{1}$ and $V_{2}$ is the total volume of the chamber $A$ and chamber $B, V_{10}$ and $V_{20}$ are"dead volume" of chamber $A$ and chamber $B$.

Hydraulic cylinder force balance equation can be expressed by:

$$
p_{\mathrm{A}} A_{1}-p_{\mathrm{B}} A_{2}=M \ddot{x}+B_{\mathrm{c}} \dot{x}+F
$$

where $B_{\mathrm{c}}$ is damping coefficient, $F$ is the random external load force.

\subsubsection{State-space equation}

Defining the state variables $\left[x_{1}, x_{2}, x_{3}\right]=[x, \dot{x}, \ddot{x}]$, according to the above equations $Q_{\mathrm{A}}=\eta \omega D_{\mathrm{pA}}$
(1) $-p_{\mathrm{A}} A_{1}-p_{\mathrm{B}} A_{2}=M \ddot{x}+B_{\mathrm{c}} \dot{x}+F$
(7), the system state-space equations can be represented as:

$$
\left\{\begin{array}{l}
\dot{x}_{1}=x_{2} \\
\dot{x}_{2}=x_{3} \\
\dot{x}_{3}=k_{1} x_{2}+k_{2} x_{3}+k_{3} \omega+f
\end{array}\right.
$$

where

$$
k_{1}=-\left(\frac{A_{1}^{2} \beta_{\mathrm{e}}}{V_{1} m}-\frac{A_{2}^{2} \beta_{\mathrm{e}}}{V_{2} m}\right) ; k_{2}=-\frac{B_{\mathrm{c}}}{m} ; k_{3}=\frac{A_{1} \eta D_{\mathrm{pA}} \beta_{\mathrm{e}}}{V_{1} m}-\frac{A_{2} \eta D_{\mathrm{pB}} \beta_{\mathrm{e}}}{V_{2} m} ; f=-\frac{\dot{\mathrm{F}}_{\mathrm{L}}}{m} .
$$




\subsubsection{Mechanical model of the micro-crane}

The schematic diagram of the crane structure is shown in Figure 2.

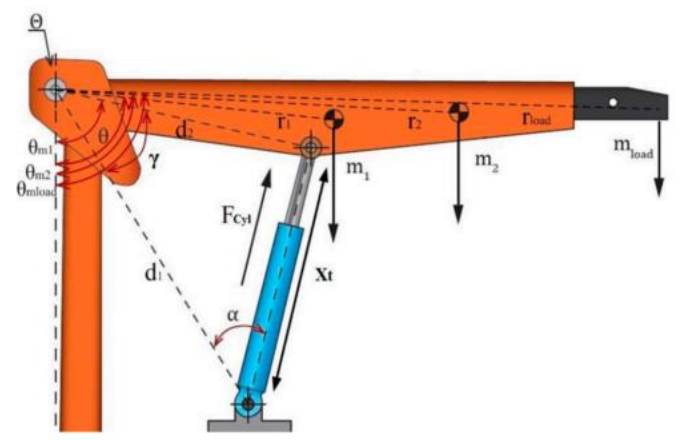

Figure 2. Crane structure diagram [10]

The load force acts on the end of the crane structure and generates torque around the joint $\Theta$. The torque balance equation is displayed as follows:

$$
\begin{gathered}
\sum M_{\theta}=J \frac{d^{2} \theta}{d t^{2}} \\
\frac{d^{2} \theta}{d t^{2}}=\left(\frac{1}{J}\right)\left[\left(-m_{1} \cdot r_{1} \cdot \sin \left(\theta_{\mathrm{m} 1}\right)-m_{2} \cdot r_{2} \cdot \sin \left(\theta_{\mathrm{m} 2}\right)-m_{\text {load }} \cdot \sin \left(\theta_{\text {mload }}\right)\right) g+F_{\text {Cyl }} \cdot \sin (\alpha) \cdot d_{1}\right]
\end{gathered}
$$

where $F_{\mathrm{Cyl}}$ is the net hydraulic force, $\mathrm{g}$ is the gravitational constant, $\alpha$ is the angle between the cylinder and the boom, $m_{\mathrm{i}}$ is a mass, $d_{1}$ and $d_{2}$ are the distance to the upper fastening point of the cylinder, $\theta_{\mathrm{i}}$ are the angles between the centre of mass and the vertical axis.

The angles $\gamma, \theta_{\mathrm{m} 1}, \theta_{\mathrm{m} 2}$, and $\theta_{\text {mload }}$ shown in Figure 2 can be determined by adding the change of $\theta$ to the measured value when the hydraulic cylinder is fully retracted:

$$
\begin{gathered}
\gamma=\gamma_{0}+\int_{0}^{\mathrm{t}} \frac{d \theta}{d t} d t \\
\theta_{\mathrm{m} 1}=\theta_{\mathrm{m} 10}+\int_{0}^{\mathrm{t}} \frac{d \theta}{d t} d t \\
\theta_{\mathrm{m} 2}=\theta_{\mathrm{m} 20}+\int_{0}^{\mathrm{t}} \frac{d \theta}{d t} d t \\
\theta_{\text {mload }}=\theta_{\text {mload } 0}+\int_{0}^{\mathrm{t}} \frac{d \theta}{d t} d t
\end{gathered}
$$

Use the sine rule given below to get the angle $\alpha$ :

$$
\sin (\alpha)=\frac{d_{2}}{x_{t}} \sin (\gamma)
$$

where $d_{2}$ is the distance to the fastening point on the cylinder, and $x_{\mathrm{t}}$ is the length of the cylinder plus the stroke of the piston. $x_{\mathrm{t}}$ is derived using the cosine rule:

$$
x_{\mathrm{t}}^{2}=d_{1}^{2}+d_{2}^{2}-2 d_{1} d_{2} \cos (\gamma)
$$


According to the derivation of equation $x_{t}^{2}=d_{1}^{2}+d_{2}^{2}-2 d_{1} d_{2} \cos (\gamma)$

(16), the hydraulic cylinder velocity can be expressed by:

$$
\frac{d x_{\mathrm{t}}}{d t}=\frac{d_{1} d_{2} \frac{d \gamma}{d t} \sin (\gamma)}{\sqrt{d_{1}^{2}+d_{2}^{2}-2 d_{1} d_{2} \cos (\gamma)}}
$$

\subsubsection{Model validation}

This subsection verifies the feasibility of the deduced state-space equation of the DDH. The parameters of the DDH are shown in Table 2. Firstly, the experimental data from reference [10] is used to verify the accuracy of the mathematical model of DDH. The comparison between the simulation results of the mathematical model and the experimental results shows that the position curve is basically consistent, as show $n$ in Figure 3(a). Then, the simulation w as performed using the state-space model, and the result is show $n$ in Figure $3(b)$. The position curve of the state-space model almost overlaps the other (mathematical model), which indicates the created state-space model has acceptable accuracy for the design of the ADRC controller.

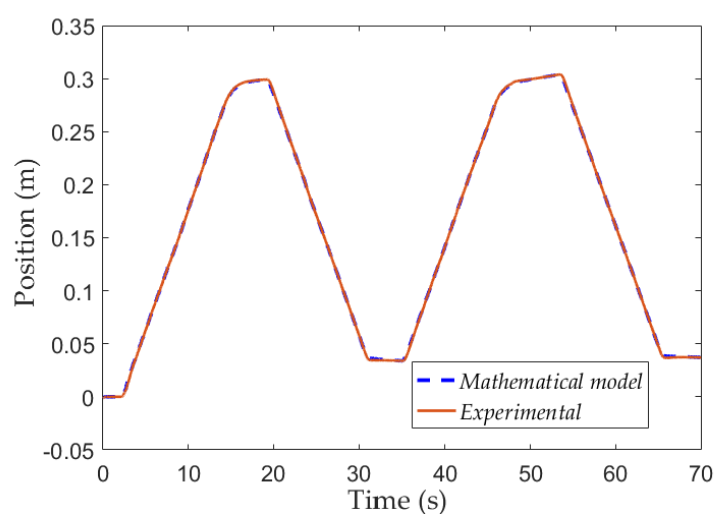

(a)

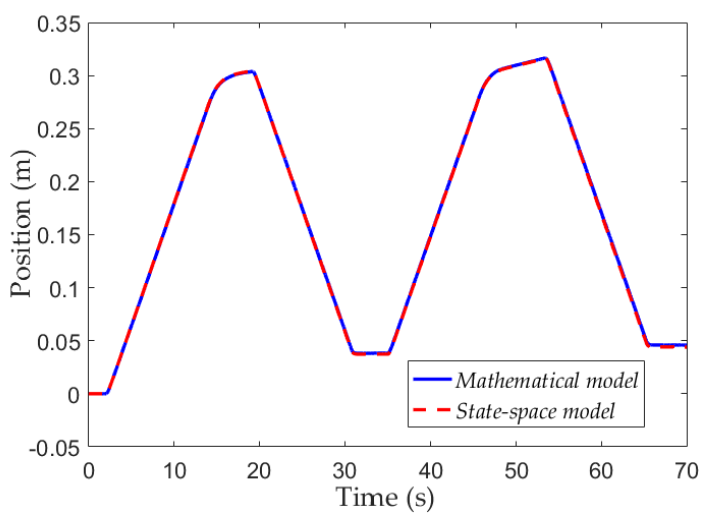

(b)

Figure 3. Validation: (a) experimental and mathematical model; (b) mathematical model and state-space model.

Table 2. Simulation parame ters of $\mathrm{DDH}$

\begin{tabular}{cccccc}
\hline Parameters & Value & Unit & Parameters & Value & Unit \\
\hline $\begin{array}{c}\text { Pump A } \\
\begin{array}{c}\text { Volumetric Displacement } \\
\left(D_{\mathrm{pA}}\right)\end{array}\end{array}$ & 13.03 & $\mathrm{ml} / \mathrm{rev}$ & $\begin{array}{c}\text { Effective bulk } \\
\text { modulus }\left(\beta_{e}\right)\end{array}$ & $7 \mathrm{e} 8$ & $\mathrm{~Pa}$ \\
$\begin{array}{c}\text { Pump B } \\
\text { Volumetric Displacement } \\
\left(D_{\mathrm{pB}}\right)\end{array}$ & 9.35 & $\mathrm{ml} / \mathrm{rev}$ & $\begin{array}{c}\text { Cylinder stroke }(L \\
)\end{array}$ & 400 & $\mathrm{~mm}$ \\
$\begin{array}{c}\text { Piston diameter of } \\
\text { hydraulic cylinder }\left(d_{\mathrm{d}}\right)\end{array}$ & 60 & $\mathrm{~mm}$ & $\begin{array}{c}\text { Damping coefficient } \\
\left(B_{\mathrm{c}}\right)\end{array}$ & 500 & $\mathrm{~N} \cdot \mathrm{s} / \mathrm{m}$ \\
\hline
\end{tabular}


Piston rod diameter of hydraulic cylinder $\left(d_{\mathrm{r}}\right)$

Load mass $(m)$
30

50 $\mathrm{mm}$

$\mathrm{kg}$
Dead volume of

chamber A ( $\left.V_{01}\right)$

Dead volume of

chamber B $\left(V_{02}\right)$
$2 e-6$

$\mathrm{m}^{3}$

$2 e-6$

$\mathrm{m}^{3}$

\section{Design of ADRC}

ADRC is a control algorithm without dependence on the system model. Its basic idea is to consider unmodelled dynamics and unknown external disturbance as "total disturbance" of the system. Further, the total disturbance is estimated and compensated. ADRC is mainly composed of three parts: the tracking differentiator (TD), the extended state observer (ESO), and the nonlinear feedback control law (NFCL) [20, 21]. Figure 4 illustrates the structure of ADRC. TD is used to arrange the transition process, and the input signal $x_{1}$ passes through the TD to give the differential signals: $x_{2}$ and $x_{3}$; ESO is used to give the estimated value of the state variables and total disturbance; $z_{1}, z_{2}$, $z_{3}$ is the estimated value of the state; $z 4$ is the estimated value of the total disturbance;NFCL is used to combine nonlinearly error betw een transition process and the estimated state variables to achieve nonlinear control strategy; $e_{1}, e_{2}, e_{3}$ is the deviation signal; $b_{0}$ is the compensation factor; $y$ is the output signal.

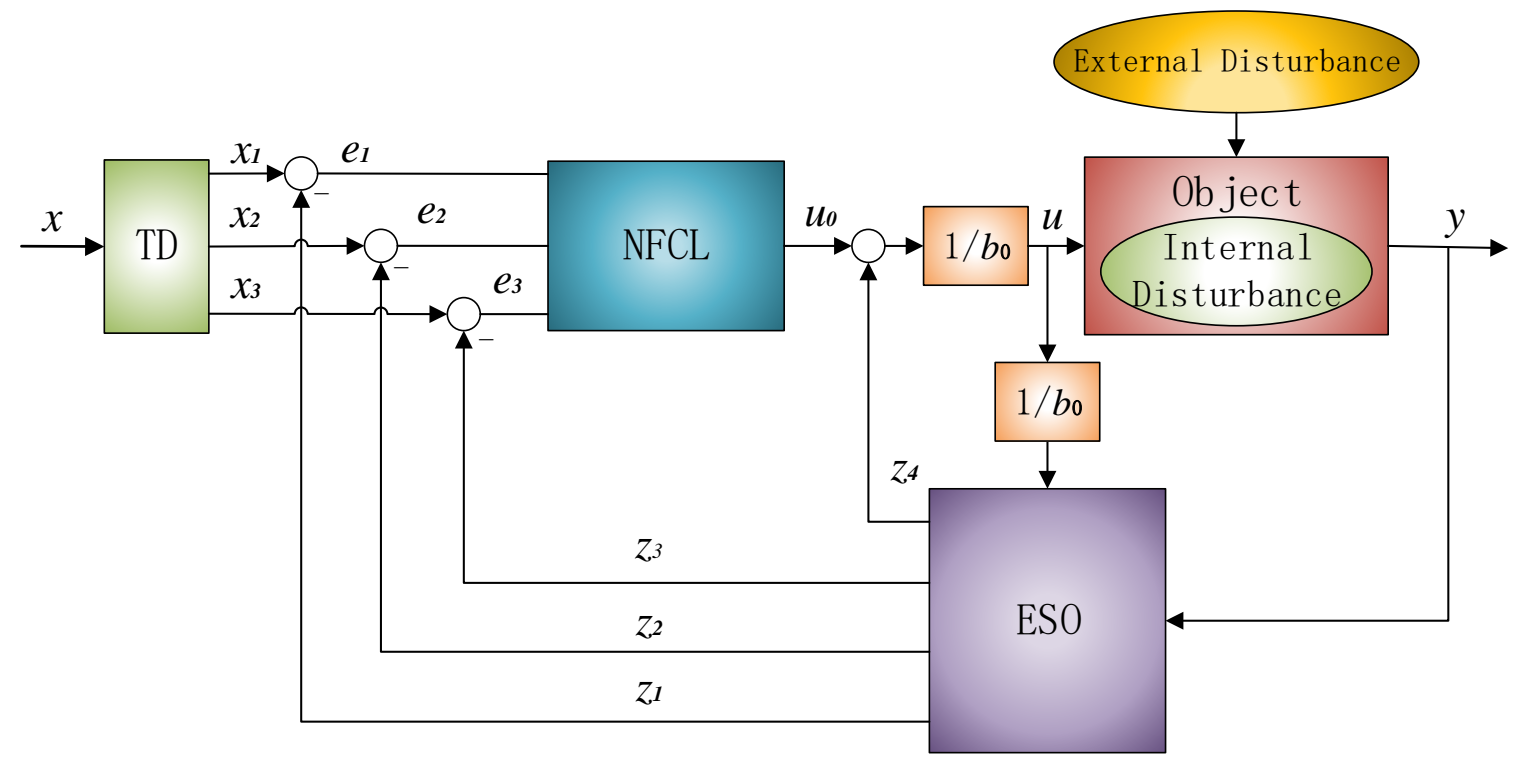

Figure 4. Structure of ADRC

\subsection{Design of TD}

TD is actually a signal processing; it can closely track the input signal and give the differential signal of the input signal. Thus, it is possible to reduce the initial error of the system and avoid overshooting caused by the sudden change of setting value [20, 21]. The DDH adopts a three-order $\mathrm{TD}$, and the discrete forms can be represented as follows:

$$
\left\{\begin{array}{l}
f h=f h a n\left(x_{1}(k), x_{2}(k), r, h\right) ; \\
x_{1}(k+1)=x_{1}(k)+T x_{2}(k) ; \\
x_{2}(k+1)=x_{2}(k)+T f h ; \\
x_{3}(k+1)=f h
\end{array}\right.
$$

where $r$ is the speed factor, $T$ is the sampling period, $h$ is the filtering factor for the in put signal; $f\left(x_{1}(k), x_{2}(k), r, h\right)$ is the fast optimal control function, and its definition is as follows: 


$$
\left\{\begin{array}{l}
f s g(x, d)=(\operatorname{sign}(x+d)-\operatorname{sign}(x-d)) / 2 \\
d=r h^{2} \\
a_{0}=h x_{2} \\
y=x_{1}+a_{0} \\
a_{1}=\sqrt{d(d+8|y|)} \\
a_{2}=a_{0}+\operatorname{sign}(y)\left(a_{1}-d\right) / 2 \\
a=\left(a_{0}+y\right) f s g(y, d)+a_{2}(1-f s g(y, d)) \\
\text { fhan }=-r\left(\frac{a}{d}\right) f \operatorname{ss}(a, d)-r \operatorname{sign}(a)(1-f \operatorname{sg}(a, d))
\end{array}\right.
$$

\subsection{Design of ESO}

The ESO is the core part of ADRC, which can track the state variables and estimate the internal and external disturbance of the system without the need for any precise mathematical model. The DDH uses a four-order ESO.

Let $m_{\mathrm{n}} 、 B_{\mathrm{cn}}, \beta_{\mathrm{en}}$ be the nominal values of $m 、 B_{\mathrm{c}}, \beta_{\mathrm{e}}$ respectively, and then can be expressed by:

$$
\begin{gathered}
k_{1 \mathrm{n}}=-\left(\frac{A_{1}^{2} \beta_{\mathrm{en}}}{V_{1} m_{\mathrm{n}}}-\frac{A_{2}^{2} \beta_{\mathrm{en}}}{V_{2} m_{\mathrm{n}}}\right) \\
k_{2 \mathrm{n}}=-\frac{B_{\mathrm{cn}}}{m_{\mathrm{n}}} \\
k_{3 \mathrm{n}}=\frac{A_{1} \eta D_{\mathrm{pA}} \beta_{\mathrm{en}}}{V_{1} m_{\mathrm{n}}}-\frac{A_{2} \eta D_{\mathrm{pB}} \beta_{\mathrm{en}}}{V_{2} m_{\mathrm{n}}} \\
f=-\frac{\dot{F}_{\mathrm{L}}}{m_{\mathrm{n}}}
\end{gathered}
$$

Let $\tilde{a}$ be the difference between the nominal value and the actual value of the parameter, $\tilde{k}=$ $k_{n}-k$, then equation $\left\{\begin{array}{l}\dot{x}_{1}=x_{2} \\ \dot{x}_{2}=x_{3} \\ \dot{x}_{3}=k_{1} x_{2}+k_{2} x_{3}+k_{3} \omega+f\end{array} \quad\right.$ (8) can be rew ritten as

$$
\left\{\begin{array}{l}
\dot{x}_{1}=x_{2} \\
\dot{x}_{2}=x_{3} \\
\dot{x}_{3}=k_{1 \mathrm{n}} x_{2}+k_{2 \mathrm{n}} x_{3}+k_{3 \mathrm{n}} \omega+\sigma
\end{array}\right.
$$

where $\sigma=\tilde{k}_{1} x_{2}-\tilde{k}_{2} x_{3}-\tilde{k}_{3} \omega+f$ represents the total disturbance of the system; in order to estimate the total disturbance, defining $x_{4}=\sigma$ as an extended state variable of the system, and assuming that $\sigma$ is differentiable, the system can be expressed by:

$$
\left\{\begin{array}{l}
\dot{x}_{1}=x_{2} \\
\dot{x}_{2}=x_{3} \\
\dot{x}_{3}=a_{1 \mathrm{n}} x_{2}+a_{2 \mathrm{n}} x_{3}+x_{4}+a_{3 \mathrm{n}} \omega \\
\dot{x}_{4}=f(x, t)
\end{array}\right.
$$

where $f(x, t)$ represents the change rate of $\sigma$. 
Let $\dot{\mathrm{z}}=\left[\dot{z}_{1}, \dot{z}_{2}, \dot{z}_{3}, \dot{z}_{4}\right]$ be the estimated vector of state $x$, then the ESO is designed as:

$$
\left\{\begin{array}{l}
e_{1}=z_{1}-y \\
\dot{z}_{1}=z_{2}-\beta_{01} e_{1} \\
\dot{z}_{2}=z_{3}-\beta_{02} e_{1} \\
\dot{z}_{3}=a_{1 n} z_{2}+a_{2 n} z_{3}+z_{4}-\beta_{03}\left|e_{1}\right|^{\frac{1}{4}} \operatorname{sign}\left(e_{1}\right)+a_{3 n} \omega \\
\dot{z}_{4}=-\beta_{04}\left|e_{1}\right|^{\frac{1}{8}} \operatorname{sign}\left(e_{1}\right)
\end{array}\right.
$$

Observer gain is simplified according to the bandwidth concept from reference [22].

$$
\beta_{01}=4 \omega, \beta_{02}=6 \omega^{2}, \beta_{03}=4 \omega^{3}, \beta_{04}=\omega^{4}
$$

\subsection{Design of NFCL}

Using the fastest control synthesis function fhan to perform nonlinear combination of errors, the algorithm can be expressed by:

$$
\left\{\begin{array}{l}
e_{1}=x_{1}-z_{1} \\
e_{2}=x_{2}-z_{2} \\
e_{3}=v_{3}-z_{3} \\
u_{0}=\beta_{1} f a l\left(e_{1}, \alpha, \delta\right)+\beta_{2} f a l\left(e_{2}, \alpha, \delta\right)+\beta_{3} f a l\left(e_{3}, \alpha, \delta\right) \\
u=u_{0}-\frac{z_{4}}{b_{0}} .
\end{array}\right.
$$

\section{Simulation results and analysis}

This section combines the DDH model, the micro-crane mechanical model, and the designed ADRC method into one model, uses sine signal and actual working position signal as inputs to the system, compares the position tracking performance with P and PI controller. The simulation parameters of DDH are shown in Table 2, and the parameters of the micro-crane are shown in Table 3.

Table 3. Micro-crane structure parameters

\begin{tabular}{ccc}
\hline Parameters & Value & Unit \\
\hline$d_{1}$ & 0.983 & $\mathrm{~m}$ \\
$m_{1}$ & 25.11 & $\mathrm{~kg}$ \\
$m_{2}$ & 21.40 & $\mathrm{~kg}$ \\
$m_{\text {load }}$ & 40 & $\mathrm{~kg}$ \\
$r_{2}$ & 0.977 & $\mathrm{~m}$ \\
$n_{\text {oad }}$ & 1.674 & $\mathrm{~m}$ \\
$\theta_{\mathrm{m} 10}$ & 0.1169 & $\mathrm{rad}$ \\
$\theta_{\mathrm{m} 20}$ & 0.1572 & $\mathrm{rad}$ \\
\hline
\end{tabular}




\subsection{Sine signal}

In order to test the performance of the adopted control method, the sine position signal was set as $x_{r}=0.15 \sin \left(\frac{2}{10} \pi t-\frac{\pi}{2}\right)+0.15(28)$, and the tracking performance of ARDC w as analyzed with or without disturbance. The simulation result without disturbance is shown in Figure 5.

$$
x_{r}=0.15 \sin \left(\frac{2}{10} \pi t-\frac{\pi}{2}\right)+0.15
$$

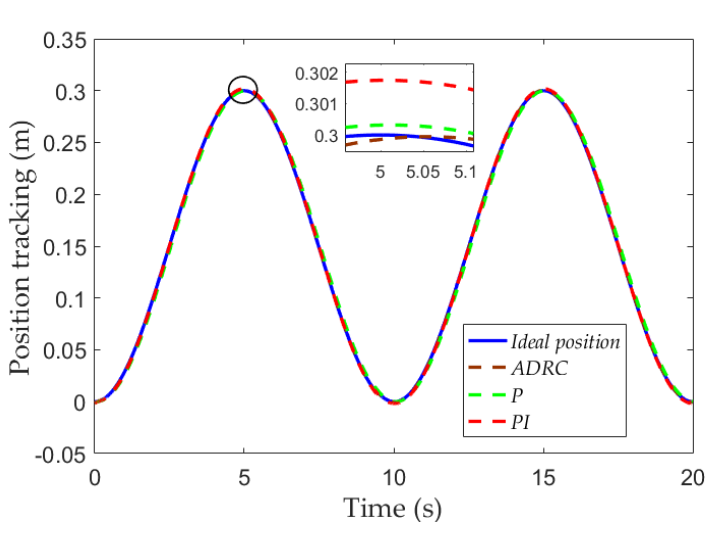

(a)

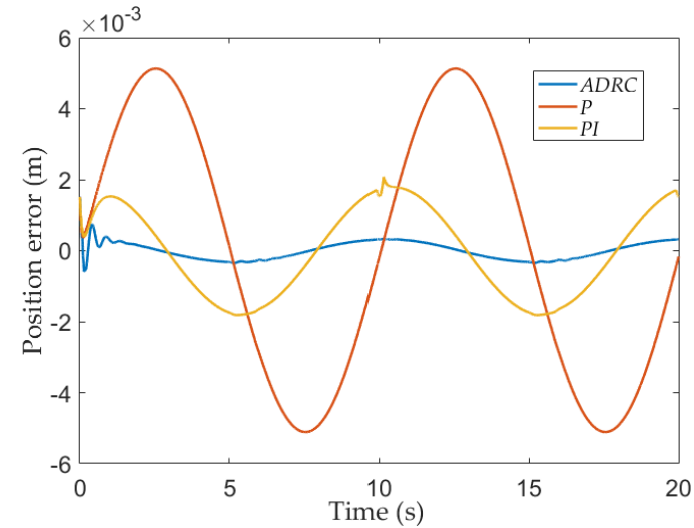

(b)

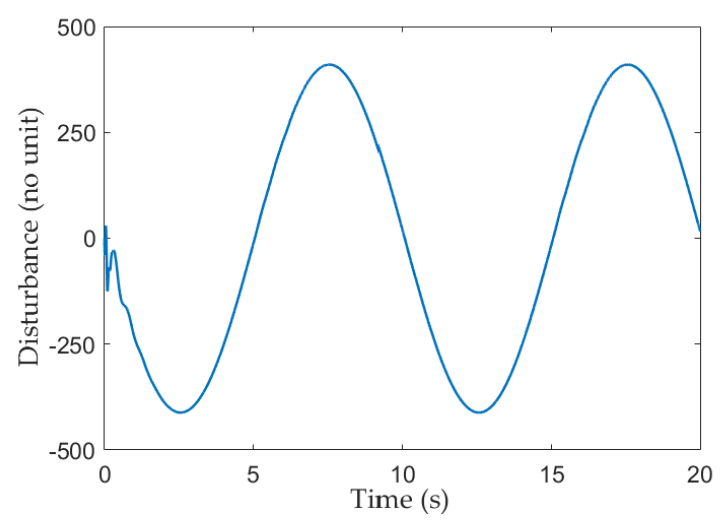

(c)

Figure 5. The sine position signal tracking without disturbance: (a) position tracking ; (b) position tracking error; (c) total disturbance observation.

The working process of the hydraulic system is often accompanied by the disturbance of the external load force. In order to compare the tracking performance and robustness with different control methods, a sudden disturbance force is added. The control tracking effect is shown in Figure 6. 


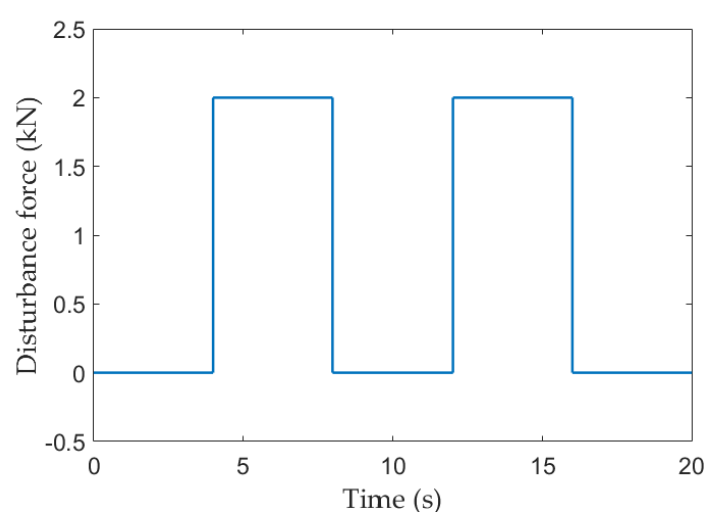

(a)

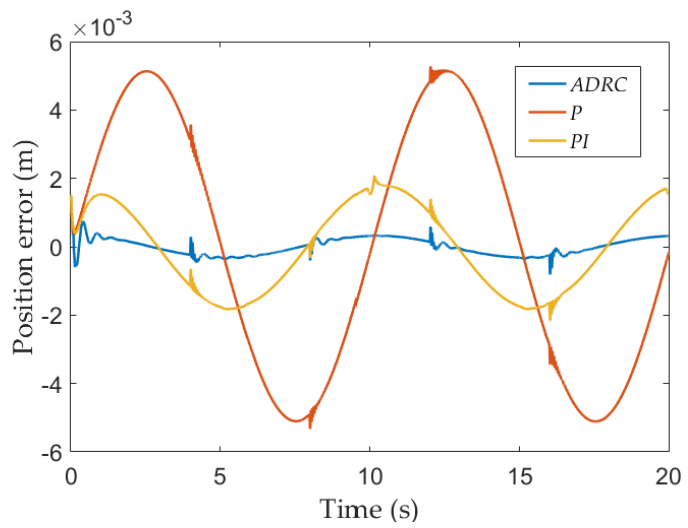

(c)

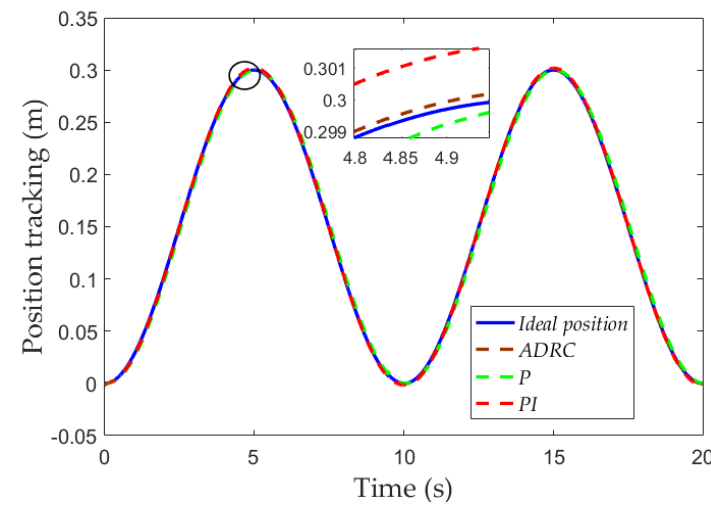

(b)

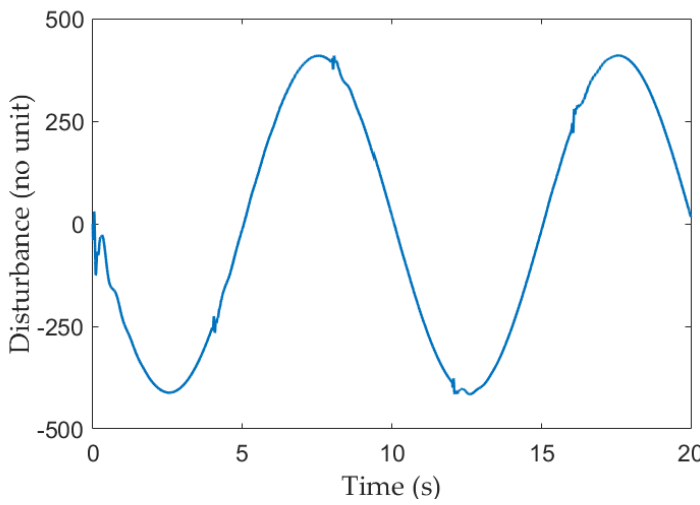

(d)

Figure 6. The sine position signal tracking with disturbance: (a) disturbance force ; (b) position tracking ; (c) position tracking error ; (d) total disturbance observation.

Table 4. Comparison of tracking error of sine position signal

\begin{tabular}{ccccc}
\hline & \multicolumn{2}{c}{$\begin{array}{c}\text { Without disturbance position } \\
\text { error/m } \\
\text { Control } \\
\text { method }\end{array}$} & $\begin{array}{c}\text { With disturbance position } \\
\text { error } / \mathrm{m}\end{array}$ \\
\cline { 2 - 4 } & $\begin{array}{c}\text { Root mean } \\
\text { square }\end{array}$ & Maximum & $\begin{array}{c}\text { Root mean } \\
\text { square }\end{array}$ & Maximum \\
\hline $\mathrm{P}$ & $2.985 \mathrm{e}-3$ & $5.132 \mathrm{e}-3$ & $3.472 \mathrm{e}-3$ & $5.275 \mathrm{e}-3$ \\
$\mathrm{PI}$ & $1.262 \mathrm{e}-3$ & $2.080 \mathrm{e}-3$ & $1.223 \mathrm{e}-3$ & $2.081 \mathrm{e}-3$ \\
ADRC & $4.276 \mathrm{e}-4$ & $1.514 \mathrm{e}-3$ & $3.833 \mathrm{e}-4$ & $1.514 \mathrm{e}-3$
\end{tabular}

As shown in Figure 5, Figure 6 and Table 4, without disturbance, the maximum errors of $\mathrm{P}$ control and PI control are $5.132 \mathrm{~mm}$ and $2.080 \mathrm{~mm}$. In contrast, the maximum error of ADRC is $1.514 \mathrm{~mm}$. It can be seen that the maximum tracking error is reduced by about $70 \%$ and $27 \%$, and the root means square error is reduced by about $86 \%$ and $66 \%$ respectively. With disturbance, the maximum errors of P control and PI control are $5.275 \mathrm{~mm}$ and $2.081 \mathrm{~mm}$. In contrast, the maximum error of ADRC is $1.514 \mathrm{~mm}$. The maximum tracking error is reduced by about $71 \%$ and $27 \%$, and the 
root means square error is reduced by about $89 \%$ and $69 \%$ respectively. It can be seen that, with ADRC, certain fluctuations appears at the begining, but it will converge quickly. The position tracking error shown in Figure 5(b) and Figure 6(c) reveals that the ADRC suppresses internal and external disturbances effectively, having high position tracking precision and strong robustness.

\subsection{Actual working position signal}

The simulation was carried out using the actual working position signal as input, and the simulation result without disturbance is shown in Figure 7.

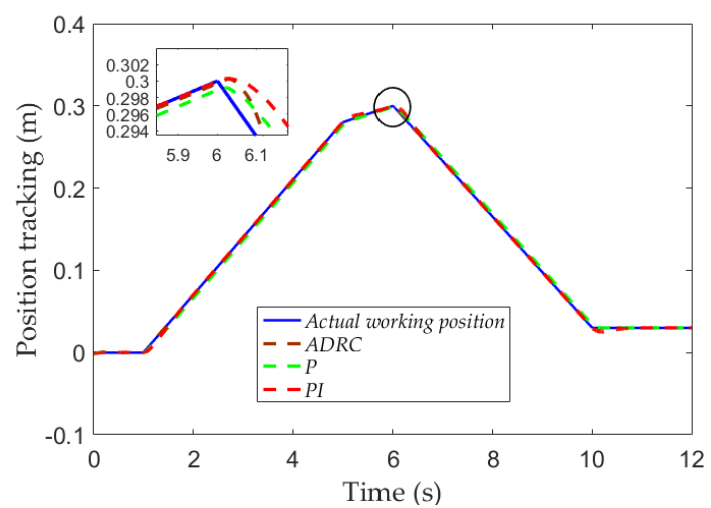

(a)

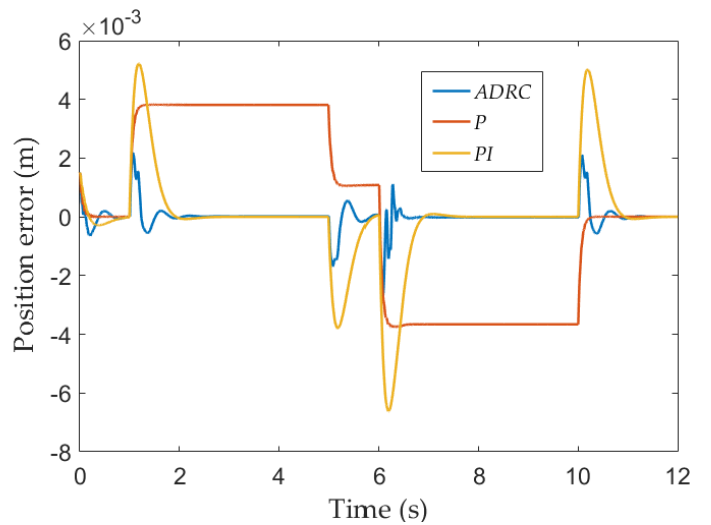

(b)

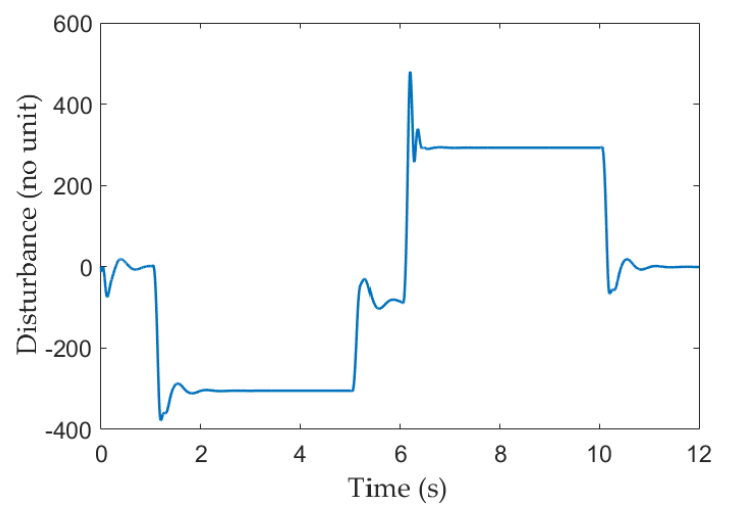

(c)

Figure 7. The actual working position signal tracking without disturbance: (a) position tracking ; (b) position tracking error ; (c) total disturbance observation.

Further, the simulation was carried out with disturbance to compare the tracking performance and robustness with varying control methods. The simulation result with disturbance is shown in Figure 8. 


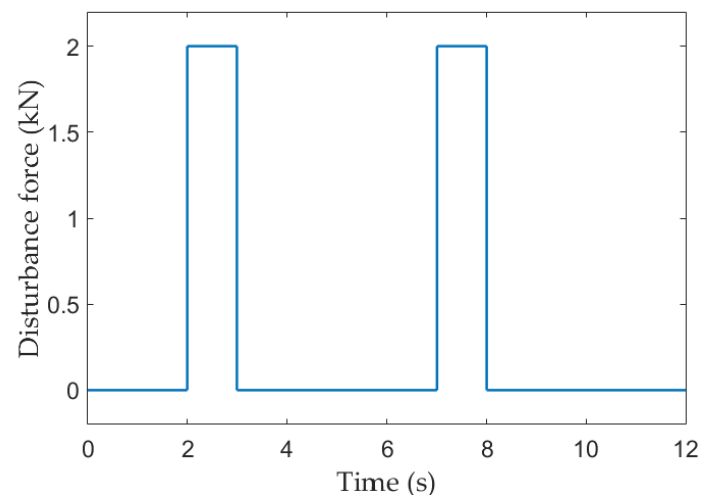

(a)

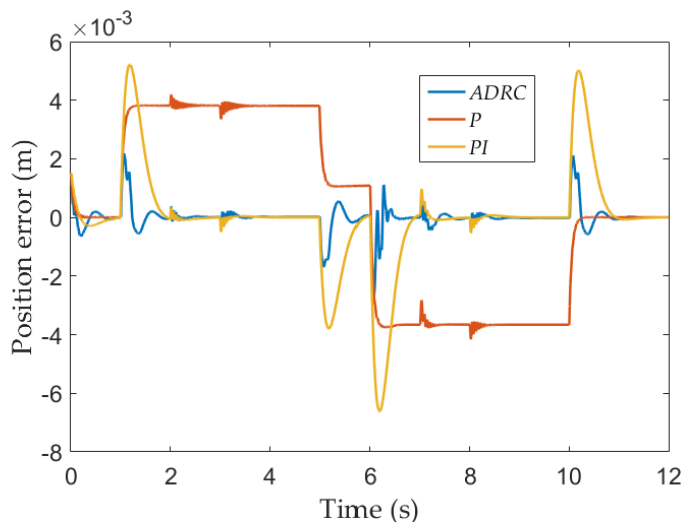

(c)

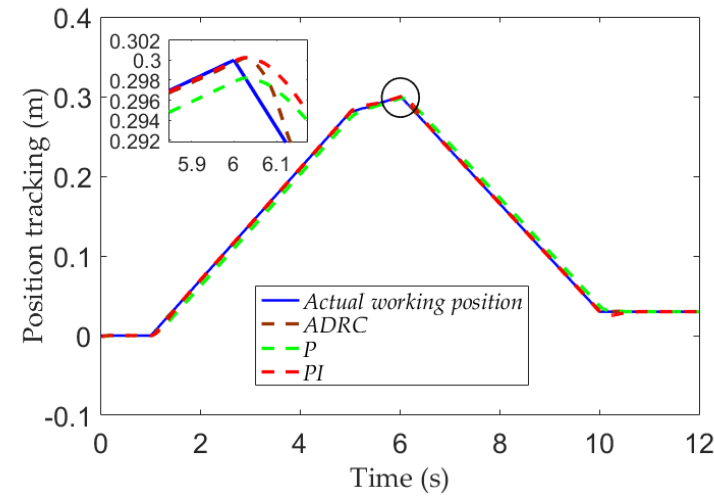

(b)

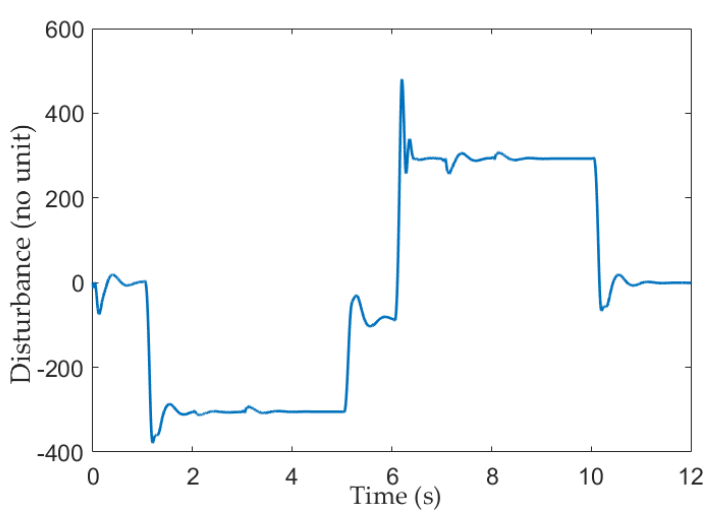

(d)

Figure 8. The actual working position signal tracking with disturbance: (a) disturbance force ; (b) position tracking ; (c) position tracking error ; (d) total disturbance observation.

Table 5. Comparis on of tracking error of actual working position signal

\begin{tabular}{ccccc}
\hline \multirow{2}{*}{$\begin{array}{c}\text { Control } \\
\text { method }\end{array}$} & \multicolumn{2}{c}{$\begin{array}{c}\text { Without disturbance position } \\
\text { error/m }\end{array}$} & \multicolumn{2}{c}{$\begin{array}{c}\text { With disturbance position } \\
\text { error } / \mathrm{m}\end{array}$} \\
\cline { 2 - 5 } & $\begin{array}{c}\text { Root mean } \\
\text { square }\end{array}$ & Maximum & $\begin{array}{c}\text { Root mean } \\
\text { square }\end{array}$ & Maximum \\
\hline P & $2.415 \mathrm{e}-3$ & $3.829 \mathrm{e}-3$ & $2.642 \mathrm{e}-3$ & $4.189 \mathrm{e}-3$ \\
$\mathrm{PI}$ & $1.955 \mathrm{e}-3$ & $5.221 \mathrm{e}-3$ & $1.873 \mathrm{e}-3$ & $5.221 \mathrm{e}-3$ \\
ADRC & $5.268 \mathrm{e}-4$ & $2.183 \mathrm{e}-3$ & $5.003 \mathrm{e}-4$ & $2.183 \mathrm{e}-3$
\end{tabular}

As shown in Figure 7, Figure 8 and Table 5, without disturbance, the maximum errors of P control and PI control are $3.829 \mathrm{~mm}$ and $5.221 \mathrm{~mm}$. In contrast, the maximum error of ADRC is $2.193 \mathrm{~mm}$, the maximum tracking error is reduced by about $43 \%$ and $58 \%$, and the root means square er ror is reduced by about $78 \%$ and $73 \%$ respectively. With disturbance, the maximum errors of $\mathrm{P}$ control and PI control are $4.189 \mathrm{~mm}$ and $5.221 \mathrm{~mm}$. In contrast, the maximum error of ADRC is $2.183 \mathrm{~mm}$. The maximum tracking error is reduced by about $48 \%$ and $58 \%$, and the root means square error is reduced by about $81 \%$ and $73 \%$ respectively. The position tracking error shown in Figure $7(\mathrm{~b})$ and 
Figure 8(c) reveals that the ADRC suppresses internal and external disturbances effectively, having high position tracking precision and strong robustness.

In summary, the simulation results shows the proposed ADRC control method has better tracking performance and stronger robustness.

\section{Conslusions}

Aiming at the problems of uncertain parameters and unknown external disturbances in the $\mathrm{DDH}$, an ADRC controller was designed. The control method can estimate the total disturbance, including parameter uncertainty and unknown disturbance, and make compensation. A model was built, including the DDH, mechanism of the crane, and ADRC controller. Simulations were performed using two types of reference signal. The simulation results reveal that, without disturbance, compared with P and PI control, ADRC can reduce the maximum error by about $43 \%$ and $58 \%$, and can decrease the root means square error by about $78 \%$ and $73 \%$. With disturbance, compared with P and PI control, ADRC reduces the maximum error by about $48 \%$ and $58 \%$, and decrease the root means square error by about $81 \%$ and $73 \%$. The results show that, compared with PID control, ADRC can suppress internal and external disturbances effectiv ely, has the advantages of robustness and improves the position tracking precision.

Although the control method ADRC can improve control accuracy on the DDH based on the simulation results, it should be compared with experimental data for validation. Hence, in the near future, a test bench needs to be set up, and experiments should be performed with the proposed control method.

Acknowledgments: This work was supported by the Science Foundation for Young Scholars of Fujian Province (No.2018J05099), the Scientific Research Fund (No. GY-Z15096), Fujian Haiyuan Composite Materials Technology Co., Ltd. and the Public Service Platform for Technical Innovation of Machine Tool Industry in Fujian University of Technology.

Author Contributions: Conceptualization, S.Z., and A.G.and F.D.; methodology, S.Z. and G.A.; software, G.A.; investigation, S.Z. and G.A.; writing - original draft preparation, S.Z. and G.A.; writing - review and editing, F.D.; supervision, S.Z.; project administration, F.D.; funding acquisition, F.D. All authors have read and agreed to the published version of the manuscript.

Conflicts of Interest: The authors declare no conflict of interest.

\section{Abbreviations}

The following abbreviations are used in this manuscript:

DDH : double-pump direct driven hydraulics

ARDC: Active disturbance rejection control

TD: Tracking-differentiator

ESO:Extended state observer

NFCL:Nonlinear feedback controllaw

\section{References:}

1. Quan, L. Current State,Problems and the Innovative Solution of Electro-hydraulic Technology of Pump Controlled Cylinder. Chinese Journal of Mechanical Engineering 2008, 44, (11). 
2. Zhang, S.; Minav, T.; Pietola, M. Performance Comparison between Single a nd Double Pump Controlled Asymmetric Cylinder under Four-quadrant Operation. Nongye Jixie Xuebao/Transactions of the Chinese Society of Agricult ural Machinery 2018, 49, (012), 409-419.

3. Fu, S.; Wang, L.; Lin, T. Control of electric drive powertrain based on variable speed control in construction machine ry. Automat Constr 2020, 119, 103281.

4. Lin, T.; Lin, Y.; Ren, H.; Chen, H.; Chen, Q.; Li, Z. Development and key technologies of pure electric construction machinery. Renewable and Sustainable Energy Reviews 2020, 132, 110080.

5. Aliskan, H.; Balkan, T.; Platin, B.E. A Complete Analysis and a Novel Solution for Instability in Pump Controlled Asymmetric Actuators. Journal of Dynamic Systems Measurement E Control 2015, 137, (9), 091008.

6. Quan, Z.; Quan, L.; Zhang, J. Review of energy efficient direct pump controlled cylinder electro-hydraulic technology. Renew Sust Energ Rev 2014, 35, (jul.), 336-346.

7. Imam, A.; Rafiq, M.; Jalayeri, E.; Sepehri, N. A Pump-Controlled Circuit for Single-Rod Cylinders that Incorporates Limited Throttling Compensating Valves. Actuators 2018, 7, (2).

8. Jalayeri, E.; Imam, A.; Tomas, Z.; Sepehri, N. A throttle-less single-rod hydraulic cylinder positioning system: Design and expe rimental evaluation. Adv Mech Eng 2015, 7, (5), 1-14.

9. Zhang, X.G.; Quan, L. The Performance Analysis and Experimental Research of Multiple Oil Ports Axial Piston Pump which Able to Control the Movement of DifferentialCylinder Directly in the Closed Circuit. Advanced Materials Research 2011, 308-310, 388-400.

10. Agostini, T.; Negri, V.D.; Minav, T.; Pietola, M. Effect of Energy Recovery on Efficiency in ElectroHydrosta tic Closed System for Differential Actua tor. Actuators 2020, 9, 12.

11. Schmidt, L.; Groenkjaer, M.; Pedersen, H.C.; Andersen, T.O.Position Control of an Over II ctuated Direct Hydraulic Cylinder Drive. Control Eng Pract 2017, 64, (jul.), 1-14.

12. Schmidt, L.; Andersen, T.O.; Pedersen, H.C.; Hansen, A.H. In An Energy Efficent Hydraulic Winch Drive Conce pt based on a Speed-Variable Switched Diffe rentiakPump, ASME/BATH2017 Symposium on Fluid Power and Motion Control, Sarasota, Florida, USA, 2017.

13. Lee, L.; Chen, C.; Li, I.; Huang, J. In The positioning control of an electro-hydraulic variable rotational speed pump-controlled system using adaptive fuzzy controller with self-tuning fuzzy sliding mode compensation, IEEE International Conference on Fuzzy Systems, Taipei, Taiwan, 2011.

14. Dang, X.B.; Truong, D.Q.; Bae, J.; Ahn, K.K. An Effective Disturbance-Observer-Based Nonlinear Controller for a Pump-Controlled Hydraulic System. IEEE/ASME Transactions on Mechatronics 2019, PP, (99), 1-1.

15. Seo, H.T.; Kang, D.G.; Hong, Y.P.; Kim, K.S.; Lee, J. In Combined feedforwa rd/disturbance observer-based control of pump-controlled electro-hydrostatic actuation system, International Confe rence on Control, HICO, Gyeongju, Korea, 2016.

16. Ahn, K.K.; Nam, D.N.C.; Jin, M. Adaptive Backstepping Control of an Electrohydraulic Actuator. IEEE/ASME Transactions on Mechatronics 2014, 19, (3), 987-995. 
17. Tri, N.M.; Nam, D.N.C.; Park, H.G.; Ahn, K.K. Trajectory control of an electro hydraulic actuator using an ite rative backstepping control scheme. Mechatronics 2014, S0957415814001603.

18. Guo, Q.; Yu, T.; Jiang, D. In Adaptive backstepping design of electro-hydraulic actuator based on state fee dback control, International Confe rence on Fluid Power \& Mechatronics, Harbin, China, 2015.

19. Järf, A. Flow compensation using hydraulic accumulator in direct driven hydraulic diffe rential cylinder application and effects on energy effciency. Master's The sis, Aalto University, Espoo,Finland, 2016.

20. Gao, B.; Shao, J.; Yang, X. A compound controlstrategy combining velocity compensation with ADRC of electro-hydraulic position servo control system. Transactions of the Chinese Society for Agricultural Machinery 2014, 53, (6), 1910-1918.

21. Shuhua, Z.; Xiangzhou, W.; Ye, L.U.; Yu, W. In An Active-Disturbance-Rejection Controller for Speed Control of Variable-Dis placement Motor at the Constant Pressure Network, Procee dings of 32nd Chinese controlConferrnce, Xi'an.China, 2013; p. 5.

22. Gao, Z. In Scaling and bandwidth-parameterization based controller tuning, American Control Conference, Denver, Colorado, 2003.

(C) 2020 by the authors; licensee MDPI, Basel, Switzerland. This article is an open access article distribute $\mathrm{under}$ the terms and conditions of the Creative Commons by Attribution (CC-BY) license (http://creativecommons.org/licenses/by/4.0/). 